\title{
WIRELESS TECHNOLOGIES IN NEW ZEALAND BUSINESSES: A LONGITUDINAL ASSESSMENT
}

\author{
LIBBY ELLIOTT \\ IBM \\ Wellington, New Zealand
}

\author{
EUSEBIO SCORNAVACCA \\ University of Baltimore \\ Baltimore, MD 2120
}

\author{
STUART J. BARNES \\ , University of Kent \\ United Kingdom
}

\begin{abstract}
The impact of mobile and wireless technologies on global consumers, businesses and society over the last decade has been very substantial. New Zealand businesses have developed an innovative reputation for implementing mobility applications. In this paper we examine the development of mobile business applications in industries in New Zealand from 2004 to 2012, based on two cross-sectional studies of organizations. The paper analyses the extent of the transformation created by the implementation of mobile business applications in this period, proposes a number of conclusions and forecasts the direction for the future of such applications in this developed market.
\end{abstract}

Keywords: M-Business; Enterprise; Strategy; Benefits; Barriers

\section{INTRODUCTION}

Mobile business solutions based on wireless technologies have the potential to become a critical business tool and to revolutionize business processes $[14,17,18,38]$. Literature has highlighted mobility, efficiency and effectiveness as key benefits of wireless technology [5, 15, 22, 37, 41].

New Zealand is the most entrepreneurial country in the world; according to the Global Innovation Index [12], the country has the highest rate of business creation per thousand population in the world. New Zealand businesses are typically small, creative and receptive to new technology, thus presenting an ideal test bed for wireless solutions and market innovation [5]. Mobile phone penetration accelerated to $95 \%$ in 2009 in New Zealand, providing the platform for innovative development [19]. Wireless solutions are becoming more widely adopted in a range of applications and industries in New Zealand [5, 19, 20, 32, 35, 39]. Previous research on New Zealand businesses utilizing wireless solutions outlines key benefits as enhancement of information flows, synced employees, additional product or service offerings, customer satisfaction, productivity gains, cost reduction, ubiquity, reachability and diversification $[5,19]$. On top of these key business benefits, there have been a number of businesses that have been created around mobile business technology [20].

A study by Barnes and Scornavacca [5], published in the Journal of Computer Information Systems, strategically assessed the impact of mobile business technology on New Zealand SMEs. The main adoption barrier was found to be technological. They concluded that a reason for this might be that the available technology was still on a steep part of the development curve and falls short of the wired alternatives in terms of the user expectations [5]. The study was based on data collection in 2004 and since that time there have been no further investigations regarding the overall situation regarding mobile business technologies in New Zealand SMEs. Evidence suggests New Zealand wireless and mobile application users have moved along the development curve in terms of technological understanding [19, 32, 35], presenting an opportune time to continue investigation for future developments. Thus, it would be opportune to replicate the study in order to investigate how mobile business developments have impacted upon New Zealand businesses since their early implementation in 2004.

The purpose of this research is to understand the strategic impact of mobile business technologies on New Zealand SME's and to compare the results to a previous study conducted in 2004. The objectives are to: (1) evaluate the current state of mobile business technologies in New Zealand SMEs; and (2) to compare and contrast the change in value attributed to the implementation of new mobile business technologies during the study period.

The structure of the paper is as follows. In the next section we examine the literature on mobile business and enterprise mobility. This is followed by a discussion of the research method used in this study and the presentation of the results, including a comparison of the results in the two time periods. Finally, the paper concludes with a summary and conclusions, including implications for the future research and practice.

\section{LITERATURE REVIEW}

\section{The Value Proposition of Mobile Business}

Distributed networked computing has had a profound impact on the way businesses and society work, learn and communicate [33]. Technological forces such as the Internet and mobile device penetration, have driven intense innovation and adoption of mobile business solutions [25]. The Internet especially has grown at a phenomenal rate and proven to be an easy and efficient way to deliver a wide variety of services [33]. In parallel mobile devices have penetrated global markets, with 5.3 billion mobile phone subscriptions in 2010 [24]. As the two of the world's largest technologies collided, mobile business (m-business) evolved.

Mobile business solutions have become widely adopted by businesses to deliver a vast array of mobile solutions such as sales force automation, navigation, tracking, field force automation, wireless telemetry and mobile offices. From these solutions researchers report many business benefits including cost savings, increased productivity, greater flexibility, collaboration with remote employees, increased customer base, ubiquity and efficiency [2, 4, 11, 33, 37, 39, 43].

Mobile business applications have provided significant new value propositions, defined by Porter [30] as the relationship between supplier's offerings and consumer's purchases by identifying how the supplier fulfills the customer's needs across different customer roles. M-business promises a unique value proposition: providing interactive access to information independent of temporal and spatial limitations [2, 6, 21, 23, 29].

Clark [11] suggests that the key value propositions of m-business solutions are ubiquity, convenience, localization and personalization. First, mobile solutions grant businesses ubiquity by allowing users to communicate independently of their locations $[11,43]$. Companies and customer can interact anytime 
and anywhere, while employees are able to connect to corporate networks from remote locations [11, 42]. Second, m-business provides users with additional convenience by removing the restriction of time and space [11]. For businesses this means that employees are able to more flexibly and conveniently accomplish business tasks while away from the office [36]. Third, information can be localized using mobile devices: information can become location-specific. Mobile websites serve as points of consolidation of consumer information and can disseminate relevant information based on a user's profile including past behavior, situation, personal profile and current location. Finally, mobile devices are personalized: they are used by one sole individual. Personalized marketing driven by mobile technology can positively influence consumers' willingness to accept mobile advertising [26]. New developments in information technology and data mining make personalized messages practical and cost effective [11].

Scornavacca, Barnes and Huff [33] conclude that the value proposition of $\mathrm{m}$-business includes ubiquitous access to information, the personal and customizable nature of the device, and fit between the application and the requirements of the task and its context. As businesses achieve enhanced value of services, their customer retention and satisfaction levels increase overall leading to improved profits, positive word of mouth and lower marketing expenditure.

\section{Enterprise Mobility}

Mobility is often referred to as the most important feature in mobile business [6, 11,31,37]. Mobility in a business context can be understood as getting information or communicating through a ubiquitous network on a mobile device not fixed to any time or geographical constraints $[8,36]$.

Enterprise mobility describes various forms of mobility that an enterprise receives by adopting m-business technology. Enterprise mobility has redefined modern business; it creates new business platforms, impacts the efficiency and productivity of business processes and eliminates the need for one central location for business operations. Enterprise mobility can be divided into three main areas, temporal mobility (time), contextual mobility (context) and spatial mobility (space) [2, 23, 28, 36]. Basole [6] extends this by pointing out that while it is important to understand the potential value of being mobile, issues surrounding mobility are still explored without clear understanding of mobility. In many cases "mobile" is used in place of "wireless" and "portable" when describing mobile devices or applications; other frequently used terms include "remote" for mobile offices and "flexible" such as mobile lifestyles [6]. Understanding the underlying dimensions of mobility will assist emphasis and help determine the mobility gains for a business.

To adopt a specific definition for the purpose of this study, Barnes [3] describes enterprise mobility as the integration of remote, disparate or roaming employees into the corporate infrastructure with the adoption of wireless networks and mobile devices. Barnes [3] furthers this by providing a conceptual and visual representation of enterprise mobility through the Mobile Enterprise Model (MEM). The model is used to view all dimensions and stages of enterprise mobility by looking at the strategic implications of mobile business technology. The model is broken into 3 main sections, market, process and mobility that is then categorized based on three possible positions. The market describes the value proposition in the marketplace that the wireless solution has enabled; typically it refers to changes in products, services and relationships along the supply chain. It has three levels from mobile channel access through mobile service value to mobile service creation. Process is described as the change in work configuration and process. It has three levels from automation through information to transformation. Finally, mobility is described as the level of geographical independence of the enterprise workers that the wireless solution has created. It has three levels from transient through mobile to remote.

\section{Mobile Business Applications in New Zealand in 2004}

In 2004, the first major academic study was conducted examining the perceived value of mobile business technology on New Zealand businesses [5]. This represented one of the first extensive studies of mobile business in SMEs. The study was exploratory and included case studies and a survey. The survey instrument was developed based on relevant mobile business literature and strategic frameworks, further extended and refined based on the results of a number of detailed case studies. After pre-testing, the final survey was sent out to 97 businesses in New Zealand and a third of the sample provided complete questionnaires with usable responses. The majority of the sample had less than 500 employees and wholesale trade was well represented in the sample.

In terms of technologies, nearly all respondents in 2004 had mobile phones with text messaging while a third had phones with Internet browsing capabilities, and more than $80 \%$ of respondent organizations were using laptops with wireless access to the principal operator networks, typically using a PC-card. In 2004, only one third of respondents were utilizing short-range wireless access such as Wi-Fi.

Referring to mobile applications, the majority of responses used mobile technology to gain access to corporate systems and mobile office functions, most commonly job dispatch and management, field force automation, mobile order entry, sales force automation (SFA) and mobile customer relationship management (CRM). Less than a quarter of respondents used mobile applications to alert customers via SMS and telemetry. Many applications were industry specific, with $15 \%$ in mobile marketing, stock management, mobile payments, mobile transactions and asset management.

Further questions examined the strategic impact of the wireless technology, benefits and limitations. The highest rated benefits related to supporting workers that are dispersed and remote from the corporate office, followed by increased worker productivity and information enabling better work and decisions. The main strategic advantages came in as diversification and protection of market share, while the principal barriers included the cost of technology, technology limitations and data security.

The study concluded that organizations were more focused on employee integration and individual performance improvement rather than product, service or organizational improvement. In addition, MEM [3] was used to analyze the results and demonstrated that while mobility, efficiency and effectiveness benefits in the sample were clear, they typically did not allow a level of benefit associated with business transformation and were far from 'mobile enterprise creation'.

\section{RESEARCH METHOD}

The purpose of this research is to evaluate the current state of wireless technology in New Zealand SMEs and to compare the results to a previous study conducted in 2004. Data collection in 2012 utilized the original study instrument of Barnes and Scornavacca [5] updated for the current study context. The replicated study will enable a detailed comparison and tests between the two time periods, 2004 and 2012.

Several new questions were added to the 2012 study in order to reflect the current IT artifacts being used. The additions were applied to questions regarding mobile devices (addition of "Smartphone with 3G access"), key benefits (addition 
of "Personalization of customer service" and "Increased understanding of customer base and target market"), strategic impacts (addition of "Increases consumer interactivity leading to customer satisfaction") and key barriers ("Problems maintaining software and hardware upgrade" and "Lack of specific industry examples (e.g. not aware of the solutions or benefits)") that relevant literature recognized as important. In addition to the minor changes, while the 2004 study was paper based the decision was made to move the current study to an online format. The survey questionnaire was uploaded to Qualtrics and tested before distribution.

The company database of NZ SMEs utilizing mobile business technology in 2004 contained 127 businesses. After updating the information in 2012, only 100 companies from the original database were still active as a standalone enterprise. Key contacts for the wireless technology, operations managers or CIOs, were invited to participate in the survey first via telephone and then a link sent via email. A third of the sample completed the questionnaire with usable responses - an identical response rate to the one obtained in 2004. The collected data was downloaded from Qualtrics into Excel and SPSS for analysis. The data was combined with the 2004 data and the matched samples were analyzed using descriptive statistics, ranking and independent t-tests [13].

\section{RESULTS AND ANALYSIS}

In this section, we summarize the results of the recent study and compare them with those of the 2004 study. The sample characteristics are summarized in Table 1. Overall, the size of businesses was slightly larger in 2012 (median=100-199) than 2004 (median=20-99). Notably, the 2012 sample contains businesses that are more evenly distributed across a wider range of industries. Transport and storage is particularly well represented, followed by property and business services, and

TABLE 1. Characteristics of Samples in 2004 and 2012

\begin{tabular}{|l|c|c|c|c|}
\hline Number of Employees & $\mathbf{2 0 0 4}$ & $\mathbf{\%}$ & $\mathbf{2 0 1 2}$ & \% \\
\hline $1-5$ & 2 & $6.5 \%$ & 0 & $0.0 \%$ \\
\hline $6-19$ & 3 & $9.7 \%$ & 1 & $3.0 \%$ \\
\hline $20-99$ & 12 & $38.7 \%$ & 11 & $33.3 \%$ \\
\hline $100-199$ & 2 & $6.5 \%$ & 7 & $21.2 \%$ \\
\hline $200-499$ & 5 & $16.1 \%$ & 7 & $21.2 \%$ \\
\hline $500+$ & 7 & $22.6 \%$ & 7 & $21.2 \%$ \\
\hline & & & & \\
\hline Industry & $\mathbf{2 0 0 4}$ & $\mathbf{\%}$ & $\mathbf{2 0 1 2}$ & $\mathbf{\%}$ \\
\hline Accommodation, cafes and restaurants & 0 & $0.00 \%$ & 0 & $0.00 \%$ \\
\hline Agriculture & 2 & $6.06 \%$ & 1 & $3.03 \%$ \\
\hline Communication service & 1 & $3.03 \%$ & 2 & $6.06 \%$ \\
\hline Construction & 0 & $0.00 \%$ & 2 & $6.06 \%$ \\
\hline Education & 0 & $0.00 \%$ & 1 & $3.03 \%$ \\
\hline Electricity and gas suppliers & 2 & $6.06 \%$ & 2 & $6.06 \%$ \\
\hline Finance and insurance & 0 & $0.00 \%$ & 1 & $3.03 \%$ \\
\hline Government administration and defense & 1 & $3.03 \%$ & 2 & $6.06 \%$ \\
\hline Health and community service & 3 & $9.09 \%$ & 0 & $0.00 \%$ \\
\hline Manufacturing & 1 & $3.03 \%$ & 3 & $9.09 \%$ \\
\hline Mining & 0 & $0.00 \%$ & 0 & $0.00 \%$ \\
\hline Personal & 2 & $6.06 \%$ & 0 & $0.00 \%$ \\
\hline Property and business services & 3 & $9.09 \%$ & 4 & $12.12 \%$ \\
\hline Retail trade & 2 & $6.06 \%$ & 2 & $6.06 \%$ \\
\hline Transport and storage & 2 & $6.06 \%$ & 6 & $18.18 \%$ \\
\hline Wholesale trade & 7 & $21.21 \%$ & 4 & $12.12 \%$ \\
\hline Other & 7 & $21.21 \%$ & 3 & $9.09 \%$ \\
\hline
\end{tabular}

wholesale trade. Accommodation, cafes and restaurants, and
mining are unrepresented, which is disappointing as there have been case studies and examples of successful mobile solutions in these industries [34].

in New Zealand, while Figure 2 presents the organizational areas that mobile technologies have been deployed. Laptops and tablets with Short Range Wireless (SRW) showed the largest increase wireless access and satellite navigation devices (GPS). Laptops and tablets using Long Range Wireless (LRW) such as 3G and outsell personal computers in 2012 [16], but this did not appear to have an effect on the adoption of LRW capable devices.
Mobile phones limited to simple text messaging appear to have been replaced by devices with $3 \mathrm{G}$ and wireless access and the adoption of smartphones. In major business orientated cities such
as Wellington and Auckland, the city councils have granted CBD users free Wi-Fi access [1, 40]. Satellite navigation devices had an increase in use during the study period. Such technology is often
concentrated in logistics applications [9], and the transport and storage industry is well represented in the sample.

a subtle change in what applications are being used. Sales Force Automation (SFA) along with asset management, mobile office
functions, inventory management, mobile customer relationship management $(\mathrm{CRM})$ and mobile job dispatch management all
experienced significant increases in businesses adoption. Access to corporate systems slightly decreased but it is still the most adopted application and equal with mobile office functions.
Interestingly, mobile marketing applications substantially decreased alongside mobile payment capabilities.

from mobile and wireless applications. All questions in 2012 averaged above 3 , the neutral score - a similar result to 2004 . ranking of mean benefits were apparent. The highest rated benefit related to allowing employees to work independently from the corporate office, a two place increase since 2004. Increasing employee's productivity (ranked second) was not perceived differently from 2004. Supporting geographically remote employees moved from first to third place in the rankings. An interesting point to note here is that the top three ranked benefits related to helping employees, indicating that organizations are still focused on applications that support their employees' independence. Enabling cost-efficient methods moved up 6 places (\#4=) alongside providing immediate information for more effective work decision-making. These results show that businesses are now more aware of the costefficient methods of mobile and wireless technology, which is a possible reflection of the global recession. Cost reduction has been a dominant top management concern globally when implementing mobile solutions since the financial crisis [27]. . 


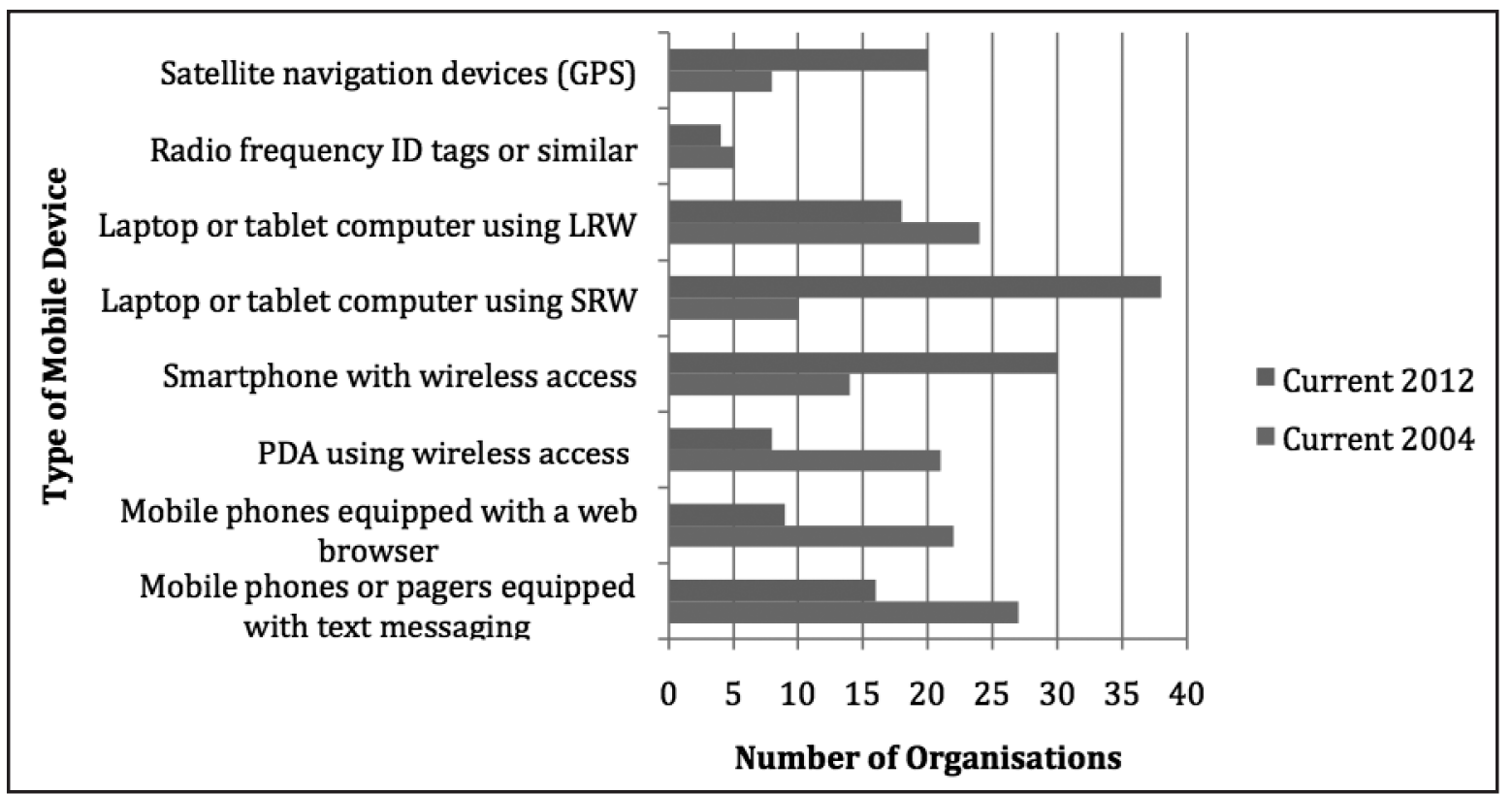

FIGURE 1. Devices Used in 2004 and 2012

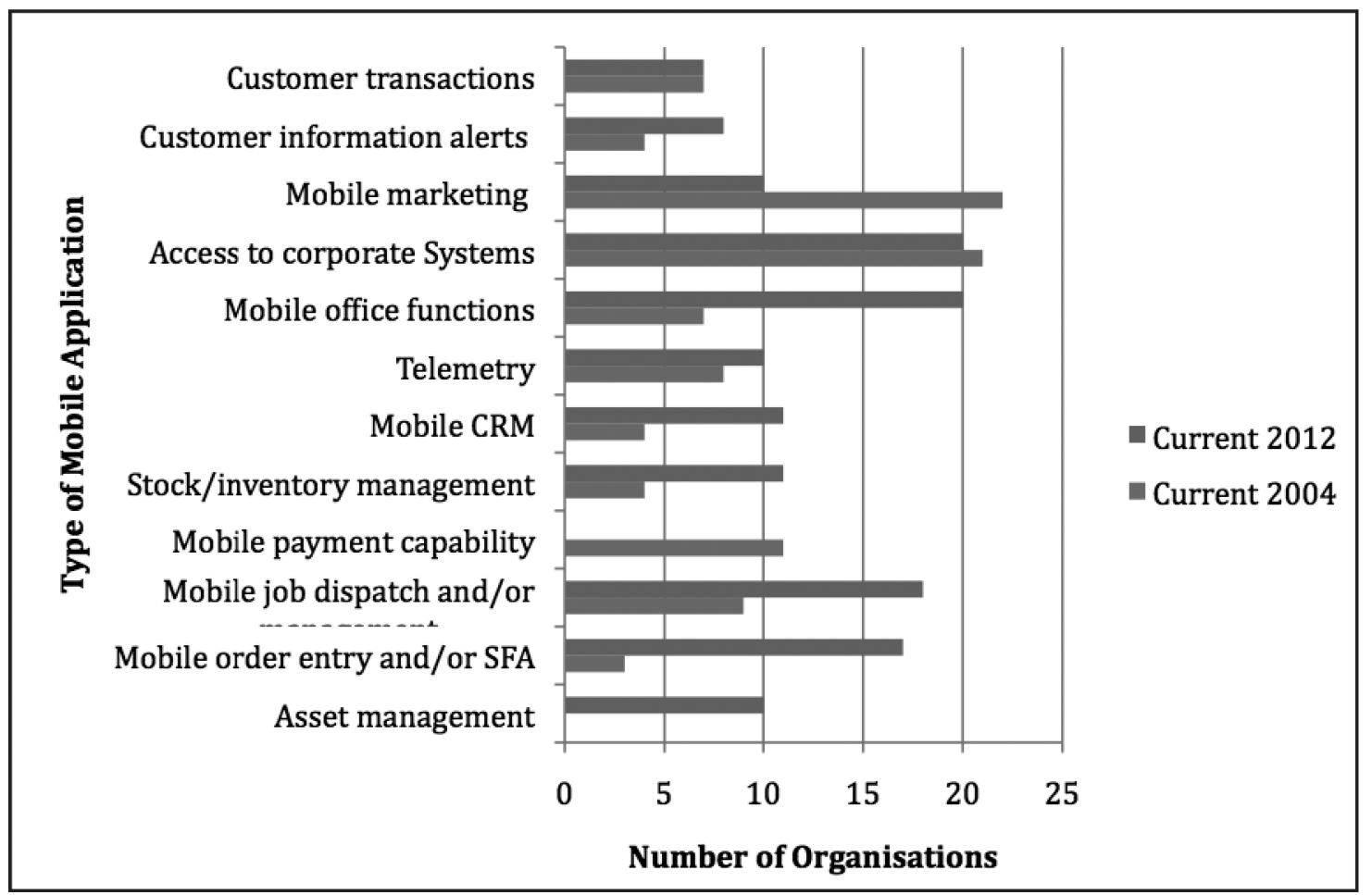

FIGURE 2. Organizational Application Areas in 2004 and 2012

In addition to the ranking analysis, independent t-tests were conducted on the samples to evaluate if there was a statistically significant difference between the 2004 and 2012 sample results. There were significant differences in the mean values of benefits for five benefits. The increase of "Enables more cost-efficient methods of working" was significant at $\mathrm{p}<.005$. Interesting, "Improves image of the organization" (ranked equal seventh) was significant at $\mathrm{p}<.001$. Other significant increases were for: "Provides considerable value-added for customers, customer service" $(\mathrm{p}<.01)$, "Enables redesign of the business" $(\mathrm{p}<.05)$ and
"Enables us to provide new and different products and services" $(\mathrm{p}<.01)$.

Beyond the key perceived benefits, the strategic impact was also evaluated and this is summarized in Table 3. These questions were designed to evaluate impact on market share as well as key strategic goals of cost, differentiation and focus. Results for 2012 show that all items score above 3 but not greatly so, although the overall mean level has increased from 3.33 to 3.52 . The highest ranked items were enabling organizations to protect or maintain their market share and diversification (ranked \#1 and 
TABLE 2. Key Benefits of M-Business Applications in 2004 and 2012

\begin{tabular}{|c|c|c|c|c|c|c|c|}
\hline \multirow[t]{2}{*}{ Benefit } & \multicolumn{2}{|c|}{ Mean } & \multirow{2}{*}{$\begin{array}{c}\text { t-test } \\
\text { (p-value) }\end{array}$} & \multicolumn{2}{|c|}{ Std. Dev. } & \multirow{2}{*}{$\begin{array}{c}\text { Rank } \\
2012\end{array}$} & \multirow{2}{*}{$\begin{array}{c}\Delta \\
\text { Rank }\end{array}$} \\
\hline & 2004 & 2012 & & 2004 & 2012 & & \\
\hline Allows our employees to work independently of the corporate office & 4.26 & 4.33 & 0.575 & 1.03 & 0.82 & 1 & 2 \\
\hline 2 Increases employee productivity & 4.29 & 4.19 & 0.474 & 0.78 & 0.74 & 2 & $\mathrm{~N} / \mathrm{C}$ \\
\hline Supports workers that are geographically remote & 4.35 & 4.15 & 0.632 & 0.8 & 0.87 & 3 & 2 \\
\hline Enables more cost-efficient methods of working & 3.71 & 4.06 & 0.011 & 1.16 & 0.79 & $4=$ & 6 \\
\hline Immediate information for more effective work and decision-making & 4.13 & 4.06 & 0.339 & 0.88 & 0.68 & $4=$ & $\mathrm{N} / \mathrm{C}$ \\
\hline Enables automation of existing processes (i.e. faster, more efficient) & 3.97 & 4 & 0.082 & 1.11 & 0.82 & 6 & $\downarrow 1$ \\
\hline $7 \quad$ Improves the image of the organization & 3.48 & 3.94 & 0.002 & 1.09 & 0.6 & $7=$ & 7 \\
\hline Reduces data entry (e.g., single data entry point) & 3.9 & 3.94 & 0.867 & 1.04 & 1.09 & $7=$ & $\mathrm{N} / \mathrm{C}$ \\
\hline 9 Allows immediate, $24-7$ response & 3.84 & 3.85 & 0.99 & 1.04 & 1 & 9 & $\mathrm{~N} / \mathrm{C}$ \\
\hline 10 Provides considerable value-added for customers, customer service & 3.6 & 3.79 & 0.002 & 1.13 & 0.7 & 10 & $\uparrow 1$ \\
\hline 11 Provides better coordination and control in the organization & 3.87 & 3.77 & 0.992 & 0.99 & 0.94 & 11 & 3 \\
\hline 12 Improves accuracy of information (i.e., reduces errors, up-to-date) & 3.97 & 3.71 & 0.378 & 1.11 & 1.1 & 12 & 6 \\
\hline 13 Enables the redesign of business processes & 3.58 & 3.7 & 0.014 & 1.03 & 0.7 & 13 & 1 \\
\hline 14 Increases employee self-esteem & 3.58 & 3.65 & 0.333 & 1.03 & 0.84 & 14 & 2 \\
\hline 15 Provides an additional channel or conduit for our products or services & 3.1 & 3.63 & 0.484 & 1.08 & 0.79 & 15 & 1 \\
\hline 16 Enables us to provide new and different products or services & 3.33 & 3.44 & 0.008 & 1.24 & 0.8 & 16 & 1 \\
\hline 17 Increased understanding of customer base and target market & N/A & 3.27 & N/A & N/A & 0.74 & 18 & $\mathrm{~N} / \mathrm{C}$ \\
\hline 18 Personalization of customer service & N/A & 3.18 & N/A & N/A & 0.78 & 17 & $\mathrm{~N} / \mathrm{C}$ \\
\hline
\end{tabular}
$\uparrow$ - Increase
$\downarrow$ - Decrease
N/C - No Chance
$=-$ Equally ranked variables

TABLE 3. Strategic Advantages of M-Business Applications in 2004 and 2012

\begin{tabular}{|c|c|c|c|c|c|c|c|c|}
\hline \multirow{2}{*}{\multicolumn{2}{|c|}{ Strategic Advantage }} & \multicolumn{2}{|c|}{ Mean } & \multirow{2}{*}{$\begin{array}{c}\text { t-test } \\
\text { (p-value) }\end{array}$} & \multicolumn{2}{|c|}{ Std. Dev. } & \multirow{2}{*}{$\begin{array}{c}\text { Rank } \\
2012\end{array}$} & \multirow{2}{*}{$\begin{array}{c}\Delta \\
\text { Rank }\end{array}$} \\
\hline & & 2004 & 2012 & & 2004 & 2012 & & \\
\hline 1 & Enables us to protect or maintain our market share & 3.47 & 3.81 & 0.04 & 1.04 & 0.69 & 1 & $\uparrow 1$ \\
\hline 2 & Provides a way for us to diversify, i.e., do different things & 3.5 & 3.7 & 0.002 & 1.07 & 0.73 & 2 & 1 \\
\hline 3 & Allows us to expand into new markets with our products or services & 3.23 & 3.56 & 0.662 & 0.82 & 0.67 & 3 & 3 \\
\hline 4 & Enables us to achieve cost leadership in our market & 3.43 & 3.47 & 0.499 & 0.9 & 0.76 & 4 & 1 \\
\hline 5 & Enables us to expand our market share & 3.27 & 3.42 & 0.133 & 0.94 & 0.66 & 5 & $\mathrm{~N} / \mathrm{C}$ \\
\hline 6 & Provides us with a unique product or service & 3.3 & 3.36 & 0.01 & 1.12 & 0.74 & 6 & 2 \\
\hline 7 & Enables us to focus on a particular target market or geographic area & 3.1 & 3.34 & 0.777 & 0.92 & 0.75 & 7 & $\mathrm{~N} / \mathrm{C}$ \\
\hline & Increases consumer interactivity leading to customer satisfaction & N/A & 3.1 & N/A & N/A & 0.85 & 8 & N/A \\
\hline
\end{tabular}

$\uparrow$ - Increase $\quad \downarrow$-Decrease N/C - No Chance

$=-$ Equally ranked variables

TABLE 4. Barriers to the Adoption of M-Business Applications in 2004 and 2012

\begin{tabular}{|c|c|c|c|c|c|c|c|c|}
\hline \multirow{2}{*}{\multicolumn{2}{|c|}{ Barrier }} & \multicolumn{2}{|c|}{ Mean } & \multirow{2}{*}{$\begin{array}{c}\text { t-test } \\
(\mathrm{p} \text {-value })\end{array}$} & \multicolumn{2}{|c|}{ Std. Dev. } & \multirow{2}{*}{$\begin{array}{c}\text { Rank } \\
2012\end{array}$} & \multirow{2}{*}{$\begin{array}{c}\Delta \\
\operatorname{Rank}\end{array}$} \\
\hline & & 2004 & 2012 & & 2004 & 2012 & & \\
\hline 1 & The high cost of new mobile technologies & 3.39 & 4 & 0.186 & 0.99 & 0.82 & 1 & $\mathrm{~N} / \mathrm{C}$ \\
\hline 2 & Technology limitations (e.g., lack of bandwidth, battery life) & 3.19 & 3.58 & 0.058 & 1.28 & 0.94 & 2 & $\mathrm{~N} / \mathrm{C}$ \\
\hline 3 & Concerns about data security & 3.1 & 3.3 & 0.114 & 1.14 & 0.88 & 4 & 1 \\
\hline 4 & Inertia to change in work practices & 2.81 & 3.16 & 0.276 & 1.01 & 0.85 & $5=$ & 1 \\
\hline 5 & Complexity in using mobile technology & 2.84 & 3.09 & 0.359 & 1.07 & 0.95 & 7 & 2 \\
\hline 6 & Problems with purchase and post purchase support from vendors & 3.06 & 2.88 & 0.439 & 0.89 & 0.71 & $9=$ & 5 \\
\hline 7 & Lack of technological expertise in the organization & 2.68 & 2.88 & 0.137 & 0.98 & 0.79 & $9=$ & 2 \\
\hline & Lack of top management support & 2.26 & 2.81 & 0.45 & 1.12 & 1 & 11 & 2 \\
\hline & The high cost of new mobile technologies & 3.39 & 4 & 0.186 & 0.99 & 0.82 & 1 & $\mathrm{~N} / \mathrm{C}$ \\
\hline & Technology limitations (e.g., lack of bandwidth, battery life) & 3.19 & 3.58 & 0.058 & 1.28 & 0.94 & 2 & $\mathrm{~N} / \mathrm{C}$ \\
\hline & Concerns about data security & 3.1 & 3.3 & 0.114 & 1.14 & 0.88 & 4 & $\downarrow 1$ \\
\hline
\end{tabular}

$\uparrow$ - Increase $\quad \downarrow$-Decrease N/C - No Chance

\#2 respectively). Market share expansion (\#3) moved up three places since 2004. The additional strategic benefit of customer satisfaction did not alter the overall ranking. Once again an independent t-test was used to compare mean values in 2004 and 2012. Only three strategic advantages had changed significantly during the study period, the top two, mentioned above, plus "Provides a way for use to diversify" $(\mathrm{p}<.01)$.
The final set of questions in the survey related to the barriers respondents experienced in the adoption of $\mathrm{m}$-business applications. The results are shown in Table 4. Two additional barriers were added in the 2012 survey. The results in 2012 were clustered above and below 3 , the neutral score. The median is 3.16 which was a minimal increase from 2004 (2.91). The high cost of mobile technologies and technological limitations, 
ranked first and second, remained unchanged. Cost and technical issues are common reasons for adoption barriers of mobile or wireless solutions [7, 10]. The additional barrier of maintaining software and hardware entered the ranking at third, followed by data security, which fell a place to fourth. The remaining items were neutral or below, indicating that respondents did not see them as problematic. Once again top management support (\#11) was ranked the lowest; implying that the adoption of mobile and wireless solutions was driven by top management. An independent t-test was conducted on the data but no significant differences were found between 2004 and 2012.

\section{DISCUSSION}

Let us examine the 2012 sample using MEM analysis: market; process; and mobility [3]. The current state of mobile and wireless applications in New Zealand has a high focus on mobility followed by the process rather than the market dimension and adding value. Mobility is most highly ranked and it is clear that the organizational focus is on individual performance improvement and employee integration into the corporate infrastructure. There is substantial evidence that suggests businesses are still providing applications at the transient level or to temporarily mobile employees.

Process is a significant area of impact for organizations in New Zealand. Many applications continue to automate existing processes for efficiency gains and increased productivity. Increased productivity was ranked highly which confirms that organizations focus on employee's performance. Applications such as mobile office functions and SFA are typical example of applications for both automating processes as well as improving information for fully-informed decision making.

There is evidence of mobile channel access with the adoption of mobile office functions and access to corporate systems. The mobile applications granted businesses with an addition channel with no significant difference in the service offered. There was little evidence to suggest that the mobile solutions extended into mobile service value or mobile service creation. In 2004, there was little indication that the applications had any impact on the value proposition.

Overall, the MEM in 2012 is similar to 2004. In 2004 the applications were not as developed and although the evidence was there in the processes, the strategic benefits were not as strong. Furthermore, the applications in 2004 appear to be predominantly used as necessary tool of competition rather than as a means of expanding existing boundaries.

These results may yield some insights on the adoption of mobile applications among New Zealand SMEs. While the assessment of the adoption and diffusion of information systems generally emphasizes the dominance of human issues, both surveys suggest that the main difficulties with mobile applications seem to be related technological platform and cost. This might be a reflection that individuals' expectations might still be based on a caparison of the technological capabilities and cost of stationary and mobile technologies. These issues may change overtime as the convergence of wired as wireless information systems progresses towards a fully ubiquitous digital ecosystem.

\section{CONCLUSIONS}

The combined success of the Internet and mobile devices has enabled mobile business to flourish at an impressive growth rate. The rapid growth of these mobile technologies will continue to proliferate, furthering the strategic impact and increasing opportunities for businesses. New Zealand has a reputation of a high level of entrepreneurship and innovative solutions. Using the results of a survey of New Zealand SMEs, this study examines the changing impact of mobile business technology on organizations in terms of benefits, strategic advantage and key barriers to adoption.

The results of the study indicate that businesses have increased employees' capabilities by adopting smartphones, laptops and tablets with wireless access. Mobility, efficiency and productivity benefits of the applications were clear in the respondent organizations in 2012. Organizations perceived the key benefits of adopting mobile or wireless solutions to be related to employees and their integration to the corporate infrastructure. In addition, New Zealand organizations see diversification, protection and maintain market share to be important benefits of mobile applications. Organizations indicated that cost and technical issues were most restrictive in the adoption of mobility solutions. Perhaps unsurprisingly, the adoption of mobile and wireless solutions appeared to be typically driven by top management.

Despite evidence in the literature suggesting that New Zealand wireless and mobile application users have moved along the development curve in terms of technological understanding $[19,32,35]$, the actual results between the 2004 and 2012 studies have perhaps not changed as much as one would suspect. As demonstrated in the result section, the overall average levels of benefits, strategic advantage and barriers are not significantly different. However, there is a notable change in the perceived level of specific items, including a significant increase in benefits related to value-added in customer service, improving the image of the organization, providing new and different products or services, and enabling more cost-efficient methods of working.

The research is limited due to its sample size, geographic location and the convenience sampling approach, but nevertheless provides a rare insight into changing use of mobile business technologies within the SME sector in a developed economy. Future research will continue to monitor the development of mobile technologies in New Zealand businesses. Mobile devices and applications are continuously being developed and therefore the impacts on businesses should progress in parallel. Future studies will particularly focus upon the further development of enterprise mobility as businesses are expected to focus on deeper levels of service creation and transformation of business processes.

\section{REFERENCES}

[1] Auckland City Council. (2012). High Speed Internet - About the City: Auckland City Council. Available at http://www. aucklandcity.govt.nz/auckland/economy/internet/cbd.asp. Retrieved 2 February, 2012.

[2] Barnes, S. J. Mbusiness: The Strategic implications of Mobile Communications, Butterworth-Heinemann, Oxford. England, 2003, 264 p.

[3] Barnes, S. J. "Enterprise Mobility: Concepts and Examples," International Journal of Mobile Communications (1:4), 2003, p. 341-359.

[4] Barnes, S. J., \& Huff, S. L. "Rising Sun: IMode and the Wireless Internet," Communications of the ACM (46:11), 2003, p.78-84

[5] Barnes, S. J., \& Scornavacca, E. "Wireless Applications in New Zealand Businesses: A Strategic Assessment," Journal of Computer Information Systems (47:1), 2006, p.46-55.

[6] Basole, R. C. "Organisational Transformation: Opportunities and Challenges - Mobilizing the Enterprise: A Conceptual Model of Transformational Value and Enterprise Readiness," $26^{\text {th }}$ ASEM National Conference Proceedings, Georgia, Atlanta: 2005, p. 364-372.

[7] Bouwman, H., Carlsson, C., Moline-Castillo, F. J., \& Walden, P. "Barriers and Drivers in the Adoption of Current and Future Mobile Services in Finland," Telematics and Informatics (24:2), 2007, 145-160. 
[8] Chatterjee, S., \& Sarker, S. "Revisiting "Collaboration" Under Conditions of "Mobility,"” Proceedings of the 40th Hawaii International Conference on System Sciences, Honolulu, Hawaii: January 2007, p. 1530 - 1605

[9] Chen, Z., Zhu, L., \& Teng, Y. "Application of GIS/GPS Technology in Mobile Logistics Public Information Platform,' International Conference on Logistics Engineering and Intelligent Transportation Systems (LEITS), Wuhan, China: November 2010, p. 1-4.

[10] Chipchase, J. Reducing Illiteracy as a Barrier to Mobile Communications, The MIT Press, Cambridge, Massachusetts, 2008, p. $79-89$.

[11] Clarke, I. "Emerging value propositions for M-commerce," Journal of Business Strategies (18:2), 2001, p. 133 - 148.

[12] Dutta, S. and Lanvin, B. "The Global Innovation Index 2013: The Local Dynamics of Innovation," WIPO, 1:1, p. $1-417$.

[13] Field, A. Discovering Statistics Using SPSS (3rd ed.), Sage Publications Ltd, London, England, 2009.

[14] Fraunhalz, B., \& Unnithan, C. "Critical Success Factors in Mobile Communications: A Comparative roadmap for Germany and India," International Journal of Mobile Communications, (2:1), 2004, p. 87 - 101.

[15] Frodigh, M., Parkvall, S., Roobol, C., Johansson, P., \& Larsson, P. "Future-Generation Wireless Networks," IEEE Personal Communications (8:5), 2001, p. 10 - 18.

[16] Gaudin, S. (2010) Tablets expected to Clobber PC Sales in 2011. Available at http://www.computerworld.com/s/ article/9198381/Tablets expected to clobber PC sales in 2011. Retrieved 15 February, 2012.

[17] Gruhn, V., Köhler, A. and Klawes, R. "Modelling and analysis of mobile business processes," Journal of Enterprise Information Management (20:6), 2007, p. 657 - 676.

[18] Hamerman, P. D. Applications Will Empower Enterprise Business Processes. MA Forrester Research, Cambridge, Massachusetts, 2010.

[19] Herrera, F., \& Scornavacca, E. "Mobile technologies in the New Zealand Real-Estate industry (1:2), Journal of Advanced Pervasive and Ubiquitous Computing, 2009, p. $19-28$

[20] Innes, D., Barnes, S. J., \& Scornavacca, E. "The Impact of Wireless Field Force Automation on New Zealand Trade Organisation," Proceedings of the Fourth International Conference on Mobile Business, Sydney, New South Wales, 2005, p. $49-55$.

[21] Jeffcoate, J., Chappell, C., \& Feindt, S. "Best practice in SME adoption of e-commerce," Benchmarking. An International Journal (9:2), 2003, p. $122-132$.

[22] Barnes, S. J. \& Scornavacca E. Unwired Business: Cases in Mobile Business, IRM Press, London, England, 2006, p. 124-139.

[23] Kakihara, M., \& Sorensen, C. "An Extended Perspective Mobility," 35th Hawaii International Conference of System Sciences, Honolulu, Hawaii, 2002, p. $1-11$.

[24] Kovic, I., \& Lulic, I. "Mobile phone in the Chain of Survival," Resuscitation (82:6), 2011, p. 776 - 779.

[25] Kumar, S., \& Zahn, C. "Mobile Communications: Evolution and Impact on Business Operations," Technovations (23), 2003 , p. $515-520$.

[26] Lee, T. M., \& Jun, J. K. "Contextual perceived value? Investigating the role of contextual marketing for customer relationship management in a mobile commerce context," Business Process Management Journal (13:6), 2007, p. 798 -814 .
[27] Luftman, J., \& Zadeh, H. S. “ Key information technology and management issues," Journal of Information Technology (26), 2011, p. $193-204$.

[28] Nah, F., Siau, K., \& Sheng, H. "The value of mobile applications: A utility company study," ACM Press (48:2), 2005, p. $85-90$.

[29] Passerini, K., Patten, K. P., \& Bartolacci, M. "Small and Medium Enterprises and the Mobile Revolution: Looking Forward," Wireless Telecommunications Symposium, 2007, p. $1-6$.

[30] Porter, M.E. On Competition, Harvard Business School Press, Boston, Massachusetts, 1998.

[31] Scornavacca, E. "An Investigation of the Factors that Influence Individual Adoption of Mobile Information Systems in the Workplace", PhD Thesis, Victoria University of Wellington, New Zealand, 2010.

[32] Scornavacca, E., \& Al-Dabbagh, B. "The Challenge of Meeting Users' Requirements of a Mobile Accounting Information System," International Conference is Mobile Business, Como, Italy, 2011, p. $105-113$.

[33] Scornavacca, E., Barnes, S. J., \& Huff, S. L. "Mobile business research, 2000-2004: Emergence, current status, and future opportunities," The 13th European Conference on Information Systems, Regensburg, Germany, 2005.

[34] Scornavacca, E., Prasad, M., \& Lehmann, H. "Exploring the Organisations Impact and Perceived benefits of Wireless Personal Digital Assistants in Restaurants," International Journal of Mobile Communication (4:5), 2006, p. 558 - 567.

[35] Scornavacca, E., Prasad, M., \& Lehmann, H. "Critical Success Factors for Wireless Hospital Bed Management Systems: The case of MARGE," 19th Australasian Conference of Information Systems, Christchurch, New Zealand, 2008.

[36] Siau, K., \& Shen, Z. "Mobile Communications and Mobile Services," International Journal of Mobile Commerce (1:2), 2003, p. $3-14$.

[37] Tilson, D. "Towards a Theoretical Framework for Studying the Effect of Mobile-ICT on Coordination," Proceedings of the 40th Hawaii International Conference on System Sciences, Honolulu, Hawaii, 2007, p. $1530-1605$.

[38] Van der Aalst, W. M. P. and van Hee, K.M. Workflow Management: Models, Methods, and Systems, MIT Press, Cambridge, Massachusetts, 2004.

[39] Walker, B., \& Barnes, S. J. "Wireless sales force automation: concept and cases," International Journal of Mobile Communications (3:4), 2005, p. 411 - 427.

[40] Wellington City Council. (2012) Wellington Free Wi-Fi Network. Available at http://cbdfree.co.nz/. Retrieved 2, February 2012.

[41] Wintergreen Research. Business Process Management (BPM) Cloud, Mobile, and Patterns: Market Shares, Strategies, and Forecasts, Worldwide, 2013 to 2019, Wintergreen Research, Inc., Lexington, Massachusetts, 2013.

[42] Zhang, J. J., \& Yuan, Y. "M-Commerce versus Internet-Bases E-Commerce: The Key Differences," Eights Americans Conference of Information Systems, 2002, p. 1892 - 1900.

[43] Zhang, J. J., Yuan, Y., \& Archer, N. "Driving Forces of M-Commerce Success," Journal of Internet Commerce (1:3), 2002, p. $81-104$. 